\title{
ASSISTÊNCIA DE ENFERMAGEM ÀS ADOLESCENTES GRÁVIDAS
}

\section{ARTIGO DE REVISÃO}

FONSECA, Jocimara Machado ${ }^{1}$

FONSECA, Jocimara Machado. Assistência de enfermagem às adolescentes grávidas. Revista Científica Multidisciplinar Núcleo do Conhecimento. Ano 04, Ed. 09, Vol. 03, pp. 92-114. Setembro de 2019. ISSN: 2448-0959, Link de acesso: https://www.nucleodoconhecimento.com.br/saude/adolescentes-gravidas

\section{RESUMO}

Este estudo tem como objetivo entender qual o papel da equipe de enfermagem na assistência às adolescentes grávidas. Trata-se de uma pesquisa bibliográfica de tipo revisão de literatura e documental; as fontes de dados pesquisadas para elaboração desse estudo teve como base artigos científicos, revistas de enfermagem, diretrizes, sendo adotado como critérios de inclusão estar na íntegra para leitura, em língua portuguesa, onde abordou 0 assunto proposto. $O$ presente trabalho fala sobre a gravidez na adolescência, o que isso pode causar na vida dessas mulheres; os métodos contraceptivos e o motivo de algumas não aderirem estes métodos; além da importância do profissional enfermeiro na vida destas gestantes jovens e como é realizada a assistência de enfermagem a essas adolescentes. Portanto, conclui-se com esse estudo, que a gravidez na adolescência está diretamente relacionada aos fatores sociais, emocionais, econômicos e culturais. Sendo assim a assistência de Enfermagem torna-se um vínculo entre os jovens e o mundo exterior para minimização do número de gestações na adolescência, uma vez que o ESF local passa a ser uma referência, buscando sempre compreender e responder qual o papel da equipe de enfermagem nesta assistência afim de promover a qualidade de vida.

Palavras-chave: Adolescência, gravidez, cuidados de enfermagem.

\footnotetext{
${ }^{1}$ Graduada em Enfermagem.
} 


\section{INTRODUÇÃO}

A assistência voltada as mulheres é ainda hoje uma preocupação de saúde pública devido ao aumento da incidência de câncer seja de colo do útero ou mama, dentre as problemáticas temos ainda o aumento no número de casos de adolescentes grávidas que traz como fator de risco a mortalidade materna. O crescimento do número de jovens grávidas, está relacionado a falta de programas voltados a promoção da saúde sobre a vida sexual e a reprodução durante a transição da idade infantil para a idade adulta, ao início precoce da atividade sexual e a inversão de valores culturais.

A cada cem adolescentes na faixa etária de 15 a 19 anos, cinco tornam-se mães anualmente segundo os dados da Organização Pan-Americana de Saúde (OPAS/OMS,1992), já em dados mais recentes período de (2006 a 2015) divulgados pela Fundo de População das Nações Unidas (UNFPA), o índice é de 65 gestações para cada 1 mil meninas na mesma faixa etária, ocorrendo em qualquer época a gravidez gera modificações no contexto social da vida da mulher, trazendo mudanças e reajustes interpessoais, já na adolescência assume-se um risco ainda maior, pois é nesta fase que ocorrem as crises vitais e de existência, é um momento onde lidar com todas as modificações do seu organismo não será nada fácil, desta forma ocorre um atrito entre o físico, o social e o psicológico sendo este último o que irá gerar mais danos as jovens.

A escolha do tema e a sua abordagem justifica-se devido ao fato de querer expor de maneira sucinta à comunidade científica bem como para a sociedade, que a gravidez na adolescência ainda possui índices alarmantes, e que a redução dos números está longe de ocorrer, uma vez que os jovens se tornam sexualmente ativos cada vez mais cedo, tendo-se a finalidade de elaborar medidas socioeducativas para os jovens; e permitir que estudiosos desta área compreendam um pouco mais sobre a temática.

Foi constatado que muitos jovens, não conhecem os métodos contraceptivos e/ou conhecem, mas possuem pouco ou nenhum acesso a estes materiais ou as informações pertinentes relacionados a estes como seu uso, mecanismo de ação e formas de aquisição, questões estas que se enquadram no quadro de atividades dos 
profissionais de saúde das unidades de atenção básica, tendo sido demonstrado que existe um grande déficit na promoção da saúde e na vinculação de informações a juventude, o estudo visou responder de que forma a assistência de enfermagem está relacionada com a diminuição da gravidez na adolescência?

Objetiva-se com este trabalho entender qual o papel da equipe de enfermagem na assistência às adolescentes grávidas. Tendo como objetivos específicos: apresentar os métodos contraceptivos e os motivos que levam a não adesão destes métodos pelos jovens; identificar por meio da literatura o número de adolescentes grávidas no Brasil; e registar a função da equipe de enfermagem na captação de jovens grávidas para desenvolver atividades direcionadas no período gravídico.

Trata-se de uma pesquisa bibliográfica de tipo revisão de literatura e documental, a coleta de dados foi iniciada no período de setembro a outubro de 2017, teve um recorte temporal dos últimos onze anos (2007 a 2017). As fontes de dados pesquisadas para elaboração desse estudo teve como base artigos científicos, revistas de enfermagem, diretrizes, sendo adotado como critérios de inclusão estar na íntegra para leitura, em língua portuguesa, onde abordou o assunto proposto, através do banco de dados da Biblioteca Virtual de Enfermagem (BVS), na base de dados: Scientific Electronic Library Online (SCIELO), Centro Latino Americano e do Caribe de Informações em Ciência da Saúde (LILAC'S), Base de Dados de enfermagem (BDENF), Medical Literatura Analysis and Retrieval System Online (MEDLINE). A busca bibliográfica foi realizada por meio dos seguintes descritores: adolescência, gravidez, cuidados de enfermagem; onde após a utilização dos critérios de inclusão e filtragem obteve-se o total de 88 artigos, que passaram por leitura analítica resultando em 26 artigos de interesse objetivo para este estudo os 5 restantes tratam-se de Portarias, Leis e Decretos encontrados no site do Ministério da Saúde. Os critérios de exclusão adotados foram documentos de língua estrangeira, artigos duplicados em base de dados e documentos cujo interesse não era objetivo para este estudo. 


\section{MÉTODOS CONTRACEPTIVOS}

Como estratégia de saúde temos o planejamento familiar que é um conjunto de ações que auxilia na prevenção da gravidez indesejada estando descrita na Lei oㅜ 9.263, de 12 de janeiro de 1996, regula o $\S 7^{\circ}$ do art. 226 da Constituição Federal de acordo com esta lei em seu artigo Art. $4^{\circ}$ "O planejamento familiar orienta-se por ações preventivas e educativas e pela garantia de acesso igualitário a informações, meios, métodos e técnicas disponíveis para a regulação da fecundidade" (BRASIL, 1996).

Os métodos contraceptivos estão disponíveis para o controle da fecundidade cujo objetivo principal é impedir uma gravidez "precoce ou indesejada", estes métodos agem impedindo o encontro do espermatozoide com o ovócito secundário (maduro). Estes meios de controle na anticoncepção incluem tanto medicamentos, como procedimentos, dispositivos e com tudo o próprio comportamento adotado pelos jovens, os tipos de métodos contraceptivos são classificados como hormonais, de barreia, naturais, mecânicos e definitivos, sendo os mais utilizados por esta faixa etária a pílula anticoncepcional e a camisinha masculina (MOREIRA, 2011).

De acordo com Alves e Lopes (2008) o início da atividade sexual tem ocorrido com mais frequência entre os adolescentes devido a influências urbanas e inversão dos valores tradicionais inclusive no ressinto familiar o que tem comprometido o projeto de vida de muitos jovens. Dentre os fatores que podem influenciar na gestação precoce segundo Nascimento, Xavier e Sá (2011) é a antecipação da menarca (primeira menstruação); nível de escolaridade e socioeconômicos baixos; além da falta de conhecimento em relação ao próprio corpo. Sendo assim é necessário apresentar os métodos aos adolescentes como forma de prevenção as infecções sexualmente transmissíveis (IST's) e como meio de evitar uma gestação indesejada, uma vez que é nesta fase que se iniciam as relações sexuais. 


\subsection{MÉTODOS NATURAIS}

Tabelinha ou Calendário: Onde estima-se o período de ovulação ou período fértil para evitar o ato sexual; onde é necessário o conhecimento mulher ou adolescente sobre seu corpo e seu ciclo menstrual o qual deve se apresentar regular (BRASIL, 2013).

Coito interrompido: Consiste na retirada do órgão sexual masculino (pênis) durante o ato sexual do órgão sexual feminino (vagina) antes da ejaculação para evitar deposição do sêmen (MOREIRA,2011).

Segundo Brasil (2013) a temperatura basal faz o controle diário da temperatura corporal ao longo do ciclo menstrual, observa-se alterações fisiológicas durante o período de ovulação, estas variações variam em torno de 0,3 a $0,8^{\circ} \mathrm{C}$.

Método Billings: Observação minuciosa por parte da mulher do seu muco cervical, podendo indicar que ela esteja em seu período fértil, o aspecto desse muco é de "clara de ovo", incolor e apresenta pequena quantidade, sem odor característico possuindo elasticidade (BRASIL, 2009).

\subsection{MÉTODOS DE BARREIRAS}

A camisinha (masculina e feminina) que impedem a ação entre espermatozoides e microrganismos do sêmen com a vagina, prevenindo contra IST'S, deve ser utilizado de maneira correto devido ao risco de rompimentos durante a relação sexual.

Diafragma mais espermicida que evita a chegada dos espermatozoides as trompas, deve ser colocado junto ao colo uterino de 15 a 30 minutos antes da relação sexual e retirado 12 horas após. É um método que exige manipulação vaginal pela mulher ou por um médico para sua introdução (MOREIRA, 2011). 


\subsection{MÉTODOS HORMONAIS}

De acordo com Brasil (2011) a Pílula (anticoncepcional oral): Método de bloqueio da ovulação, deve ser associado a um método de barreia pois não previne contra IST'S, possui como desvantagens ganho de peso, tonturas ou dor de cabeça.

Pílula do dia seguinte ou de emergência (anticoncepcional oral): inibi ou retardo da ovulação o mecanismo de ação vai depender do ciclo menstrual, possui alta concentração hormonal, por isto deve se evitar usos repetitivos. Não previne contra ISTS, seu uso pode causar náuseas, cefaleia, dor abdominal, ciclos irregulares (BITTENCOURT, 2010).

Anticoncepcional Injetável: Pode ser de uso mensal ou trimestral, dificulta a ovulação, provoca acidentes vasculares, cefaleia, ganho de peso, tonturas e irregularidade no ciclo menstrual (MOREIRA, 2011).

DIU (dispositivo intrauterino): Bloqueia a fecundação e proporciona longa duração pode permanecer de (5 a 10 anos) quando de cobre e (5 anos) quando de base hormonal. Tem como risco aquisição de infecções sexualmente transmissíveis e a perfuração do útero (BRASIL, 2009).

Anel vaginal ou Adesivo transdérmico, conforme Moreira (2011), é um método de auto custo mecanismo de ação se assemelha ao da pílula anticoncepcional porem as vias seriam respectivamente vaginal e transdérmica (aplicada sobre a pele).

\subsection{MÉTODOS DEFINITIVOS}

Segundo Bittencourt (2010, p. 23-24) e Moreira (2011, p. 135-136):

Vasectomia: Procedimento cirúrgico realizado no homem, uso de anestesia local, onde ocorre ligadura dos canais deferentes que se encontram acima do escroto no homem, dura aproximadamente 20 minutos, feita por um urologista em consultório médico. É um método impede que os espermatozoides cheguem ao canal de saída, considerada cirurgia voluntária. Laqueadura tubaria ou das trompas: Procedimento cirúrgico voluntário e definitivo realizado na mulher, que 
impede o processo de fecundação através da obstrução das tubas uterinas seja por corte ou amarração. Consiste em uma cirurgia simples realizada por ginecologistas em mulheres com mais de 25 anos com no mínimo de dois filhos.

Segundo Wannmacher (2003, apud LIMA, 2017, p. 26) os contraceptivos hormonais da classe orais apresentam benefícios tais como: a regularização do ciclo menstrual, redução da tensão pré-menstrual, redução da incidência de cistos ovarianos, de câncer ovariano e endometrial e de doenças benignas das mamas.

Os métodos hormonais devem ser usados em conjunto com o preservativo masculino ou feminino, pois não oferecem prevenção as IST'S sendo facilmente encontrados em farmácias, clínicas, postos de saúde.

Mesmo após alertas de saúde para risco de doenças adquiridas sexualmente mostrase baixo a adesão aos métodos contraceptivos pelos jovens, existe uma falta de preocupação em relação ao assunto, em locais determinados o fenômeno está relacionado a falta de veiculação de informações e ao acesso ao material. Dentre as adolescentes ainda existe a falta de imposição sobre o uso preservativo no momento da relação ao parceiro seja por vergonha; ou por medo de questionamentos sobre a sua saúde. Acredita-se ainda que não haveria problema em não usar o preservativo por "confiança" no parceiro, ou por gerar desconforto diminuindo assim a sensação de prazer.

Deve-se levar em consideração que adquirir ou não os métodos de prevenção podemse estar diretamente relacionados as informações escassas e o pouco ou nenhum conhecimento de muitos adolescentes a estes meios, assim como a dificuldade em se adquirir os preservativos nas redes públicas e de atenção básica.

\section{GRAVIDEZ NA ADOLESCÊNCIA}

Segundo a Organização Mundial de Saúde (OMS) a adolescência como o período da vida a partir do qual surgem às características sexuais secundarias e se desenvolvem processos psicológicos e padrões de identificação que evoluem da fase infantil para a fase adulta, entre eles a transição de um estado de dependência para outro de relativa 
autonomia, prolongando-se dos 10 aos 20 anos incompletos e distingue-se adolescência inicial (entre 10 e 14 anos de idade) e adolescência final (na idade de 15 a 19 anos) (JATOBÁ; BASTOS,2007).

No Brasil, o Estatuto da Criança e do Adolescente (ECA), Lei 8.069, de 1990, considera criança a pessoa até 12 anos de idade incompletos e define a adolescência como a faixa etária de 12 a 18 anos de idade (artigo $2^{\circ}$ ), e, em casos excepcionais e quando disposto na lei, o estatuto é aplicável até os 21 anos de idade (artigos 121 e 142).

A adolescência é o período em que ocorre a transição da passagem da infância para a vida adulta. Neste período ocorrem transformações biológicas, psicológicas e sociais relacionadas ao crescimento físico, maturação sexual, aquisição da capacidade de reprodução que permitem o desenvolvimento de uma identidade adulta inserida no meio social (SANTOS et al., 2014, p. 106).

Podemos dizer que a adolescência nada mais é que um período de transições principalmente fisiológicos e psicológicos, abrangem inúmeras transformações inclusive corporais, no caso de adolescentes do sexo feminino a alterações ocorrem nos níveis hormonais, o que favorecem mudanças nos seios, na voz, do quadril, surgindo a menarca que seria sua primeira menstruarão, o que indica que está adolescente chegou a maturidade sexual, atingindo sua capacidade reprodutiva (MOREIRA et al, 2008).

A gravidez e/ou gestação nada mais é do que condição atual a qual a mulher se encontra, onde o produto proveniente da concepção está sobre processo de evolução e desenvolvimento. Sobre a gravidez na adolescência pode ser ressaltado as significativas transformações na vida das jovens, pois elas não estão preparadas para assumir os seguintes papeis de mulher, esposa e mãe, então impostos pela sociedade, pois a gestação nesta fase ocorre de forma precoce e sem planejamento tornando-se indesejada (NOBREGA; BEZERRA, 2010).

A gravidez neste grupo populacional vem sendo considerada, um problema de saúde pública. É comum e na maioria das vezes evitável e associado a sequelas negativas 
para as adolescentes que se tornam grávidas e para seus filhos. Pode acarretar complicações obstétricas, com repercussões para a mãe e o recém-nascido, bem como problemas psicossociais e econômicas (LANGILLE, 2007 apud DOMINGOS, 2010).

De acordo com Moreira et al. (2008, p.319):

Os conflitos vivenciados pelas adolescentes na descoberta da gravidez se dão na percepção desta gestação como um acontecimento indesejado, no medo de enfrentar tal situação perante a sua família ou companheiro, na reação dos pais com a descoberta a gravidez na adolescência e também são ressaltados no baixo nível socioeconômico familiar, determinantes na não aceitação da gravidez nessas adolescentes.

Desta forma as adolescentes viverão num mundo de dúvidas, de perspectivas e de aflições, tentarão de certa forma tornaram-se "maduras" serem responsáveis mesmo que está tentativa torne-se frustrada, buscarão meios de lidar com a gestação e as modificações de seu corpo, assim como buscarão recursos para adesão de renda seja por auxilio dos seus pais, do companheiro ou meios próprios. Muitas das jovens tentarão lidar com este processo e outras não, pois uma gravidez na juventude significaria o fim de sua "liberdade", dos seus estudos ou até mesmo de seus vínculos sociais (HOGA, 2008).

De acordo com Domingos (2010), o aborto muita das vezes é a única saída para as adolescentes e neste desafio, elas arriscam suas próprias vidas quando decidem interromper a gravidez, utilizando de quaisquer recursos que tenham em mãos. Sobre as repercussões negativas da gravidez precoce é afirmado ainda segundo Silva et al. (2012) que as consequências são identificadas como problemas no crescimento e desenvolvimento da adolescente como um todo, além das complicações no parto que geram fatores de risco ao recém-nascido como a prematuridade, o baixo peso ao nascer, baixo índice de apgar, entre outras complicações.

Entre as transformações que ocorrem durante a gestação pode-se citar a interação destas jovens com o meio aonde vivem e a sua adaptação na sociedade agora como mãe, o abandono as escolas cada vez mais frequente pode significar para estas 
descontentamento e não realização pessoal, de acordo com Menezes et al. (2012), é primordial o apoio de todos para que as jovens mãe e/ou grávidas continuem os estudos se assim desejarem, pois o abandono escolar leva ao fracasso limitando a possibilidade de construção de independência financeira.

As mudanças da vida geradas pela gravidez estão intimamente associadas ao nível socioeconômico de origem; em níveis socioeconômicos mais elevados; a gravidez gerava menos mudanças no estado civil das adolescentes; não havendo necessidade de interferir no seu plano de desenvolvimento individual. No entanto o mesmo não acontece em níveis socioeconômicos mais baixos em que a adolescente passa a ser considerada totalmente responsável pelo bebê (DINIZ; KOLLER et al., 2012, p. 311).

Segundo Priestch et al. (2011), a gravidez não planejada é responsável por uma série de agravos ligados a saúde reprodutiva materna e perinatal e apresenta diversos riscos.

As características fisiológicas e psicológicas são alteradas, nesta fase estão presentes a ansiedade e o estresse; portanto a ocorrência acarreta impactos importantes na oferta dos cuidados do pré-natal, orientação sobre o aleitamento materno e nas taxas de morbidade infantil (ARAUJO et al., 2015).

Enquanto em algumas adolescentes são gerados sentimentos caracterizados como ruins como medo, dúvida, incerteza, insegurança, tristeza, desanimo, abandono entre outros tão comuns vemos uma repercussão diferente em outro grupo de adolescentes, pois se mostraram satisfeitas, felizes, completas, alegres.

Segundo a percepção de Hoga (2008, p.5):

Em outras adolescentes os sentimentos expressos em relação a gravidez foram outros; pois muitas delas mudaram seu estilo de vida após a incorporação do papel materno elas se distanciaram das ruas e de certos amigos para se dedicarem e darem atenção aos seus filhos, estas mudanças representaram um salto qualitativo significativo na vida destas jovens predominando entre estas o sentimento de felicidade e satisfação em relação a "ser mãe". 
Os sentimentos então expressos pelas jovens dependem de certa forma da reação dos seus companheiros e demais familiares em relação a sua gestação. Os sonhos muitas vezes relatados pelas jovens e então "mamães" consiste em prioridades como promover a própria condição de vida e de seus filhos para garantir um futuro para ambos e manter a família (HOGA, 2008).

Por mais que a gravidez venha a se tornar um transtorno inclusive em sua fase inicial pela falta de apoio do próprio companheiro até então responsável também pelo ocorrido; assim como não aceitação e até mesmo negação da família a gestação, as jovens conseguem perceber mesmo que tardiamente, que se não for traçado um plano por elas e criado uma meta para que se chegue "bem" ao final deste processo; elas não serão capazes de promover meios para garantia de qualidade de vida deste ser concebido, a força de vontade e o querer cresce então dentro destas futuras mães; fazendo com que a criança passe a ser desejada, querida e amada ainda no ventre.

No entanto quando esta jovem não cria maturidade suficiente e sofre fortemente com a rejeição ou assimila que este ser se tornara um "mal", afetando diretamente suas relações, seu namoro, seus estudos, seus vínculos entre eles os laços de amizade; ela tentara dar um basta em tudo isto ou se fechara em um mundo de decepções o resto da vida, a sua saúde não será restabelecida, o que poderá acarretar transtornos, inclusive de características psicológicas. A carga recairá sobre a criança como o desapego, a falta de amor, a repulsividade, a falta de cuidados entre outros fatores considerados não aceitáveis ao desenvolvimento e crescimento deste ser considerado frágil e sem entendimento sobre o novo mundo que o espera.

De acordo com Rocha (2013, p.14):

As adolescentes, que engravidam e fazem pública uma conduta clandestina, passam rapidamente da situação de filha para a de mãe, de querer colo para dar colo, numa transformação violenta da mulher ainda em formação para uma mulher adulta, mãe, vivendo uma situação conflitiva e, em grande parte dos casos, penosa. 
"Se para a mulher adulta ser mãe é difícil, tendo dificuldade de intervir com seu companheiro, mas dificuldade terá uma adolescente para assumir o novo papel". (ROCHA, 2013, p.14)

Segundo Rocha (2013, p. 14):

É muito importante que a adolescente tenha oportunidade de juntar seus pedaços e que cumpra seu papel de mulher, adolescente e cidadã. Ela precisa estar inteira e que cumpra seu papel de mulher, adolescente e cidadã. Ela precisa estar inteira para viver o papel de mãe e permitir-se ter ou não novos relacionamentos, planejar sua atividade sexual, repensar sua vida escolar e profissional, readquirir e estimular sua autoestima para poder, como é seu direito, viver plenamente.

De acordo com a estimativa do Ministério da Saúde (MS) a partir do censo de 2000 do Instituto Brasileiro de Geografia e Estatística, no Brasil há 38.283.299 adolescentes na faixa etária de 10 a 19 anos. A fecundidade em adolescentes na faixa etária de 15 a 19 anos vem aumentando, em 1990 a cada mil adolescentes 80 delas tinham 1 filho e no ano de 2000 a cada mil, 90 possuíam 1 filho (ARAUJO et al., 2015).

No mundo cerca de $10 \%$ do total de nascimentos anuais são de adolescentes. Do total de nascidos vivos em 2000 no Brasil, foram identificados 0,9\% de nascidos vivos de mães entre 10 e 14 anos e 22,4\% de nascidos vivos de mães entre 15 e 19 anos de idade (ARAUJO et al., 2015).

Segundo o Ministério da Saúde (MS), o número de adolescentes grávidas no Brasil caiu em torno de $17 \%$ entre os anos de 2004 a 2015, as informações foram avaliadas com base no Sistema de Informação Nascidos Vivos (Sinasc), a queda apontada foi de 661,2 mil nascidos vivos no ano de 2004, para 546,5 mil no ano de 2015 entre mães adolescentes na faixa etária de 10 a 19 anos. Sendo que pertence a região nordeste a maior concentração no número de gestantes, são 180 mil nascidos o que corresponde a $32 \%$ do total, as demais posições são ocupadas pelas Região Sudeste 179,2 mil (32\%); Região Norte 81,4 mil (14\%); Região Sul 62.475 (11\%) e Centro Oeste $43.342(8 \%)$. 


\section{ASSISTÊNCIA DE ENFERMAGEM}

A gravidez durante a adolescência é um problema recorrente e atual da saúde pública, a cada ano os índices tem aumentado, a imaturidade da mãe ainda jovem e a não solidificação das mudanças alternadas em relação transição da vida infantil para adulta acarreta diversos problemas inclusive psicológicos e familiares, estas adolescentes inúmeras vezes tentam esconder a gravidez e isto dificulta a capitação destas nos programas de assistência ao pré-natal, para que haja um acompanhamento seguro do binômio mãe-filho e identificação de gestação de risco ou não para encaminhamento a unidades de referência com suporte especializado (FERREIRA; RIBEIRO, 2010).

A assistência de enfermagem que é prestada as adolescentes grávidas ocorre no setor primário de saúde as unidades de atenção básica os famosos ESF (Estratégia e saúde da Família) antes intitulada como PSF (Programa de Saúde da Família), cujo objetivo é acompanhar toda gestação a partir do conhecimento de sua existência até ao final, desde que seja comprovada que não possui riscos fetal e/ou materno.

O atendimento que é prestado pela equipe de saúde que compõe o ESF em sua rotina consiste na coleta de dados como histórico familiar, histórico de doenças atuais ou pregressas, número de gestações, histórico socioeconômico, uso de métodos contraceptivos ou não entre outras informações pertinentes a conhecer a relação saúde doença da jovem, identifica-se em semanas o tempo de gestação, faz se solicitação de exames como (ultrassonografia, preventivo e analise sanguínea) e orienta a jovem sobre cada trimestre e as modificações do seu organismo, agendando assim as posteriores consultas (retorno conforme idade gestacional).

De acordo com Silva et al. (2016), a assistência pré-natal é amparada legalmente em relação a atuação profissional do enfermeiro, para que ocorra acompanhamento integral de gestantes de baixo risco na rede básica de saúde e no Programa de Estratégia de saúde da Família, desta forma o enfermeiro se torna capaz de realizar as ações de atenção à saúde da mulher no pré-natal, esperasse de certa forma que estes profissionais se responsabilizem pelo tipo de assistência então prestada. 
De acordo com a Lei 7.498 de 25 de julho de 1986 que dispõe sobre a regulamentação do Exercício Profissional de Enfermagem e descreve que:

Ao enfermeiro cabe realizar a consulta de enfermagem e prescrição da assistência em enfermagem; como integrante da equipe de saúde: prescrever medicamentos, desde que estabelecidos em Programas de Saúde Pública e em rotina aprovada pela instituição de saúde; oferecer assistência de enfermagem a gestante, parturientes e puérperas e realizar atividades de educação em saúde (BRASIL, 1986, p. 9273).

Para que a consulta de pré-natal ocorra de forma humanizada e com qualidade, é essencial que haja organização dos serviços de saúde em todas as etapas de atendimento desde a primeira consulta então a ser realizada, obedecendo todas as normas e rotinas das instituições prestadoras dos referidos serviços. Conforme Silva et al. (2016), é necessário a preparação dos profissionais, atentos e sensíveis as necessidades das mulheres e de seus familiares; o uso de tecnologias de saúde que permitam o avanço e o bom termo de consulta, e por fim o seguimento do cuidado de maneira holística e integral.

De acordo com Silva et al. (2016, p. 4091), os limites de atuação do enfermeiro na realização da consulta pré-natal estão descritos nos seguintes subitens:

a) a atenção pré-natal centrada no modelo biomédico; b) a precariedade de recursos relativos à área física, recursos humanos e materiais; c) o desconhecimento do trabalho da enfermeira e da consulta de enfermagem; d) a necessidade de maior qualificação profissional; e) o modelo educativo pautado no modelo tradicional; f) a falta de sistematização da assistência.

A assistência que é prestada durante todo o período gravídico não deve ficar restrito ao modelo biomédico, pois acaba se tornando uma assistência mecanizada voltada apenas aos aspectos biológicos e fisiológicos, o que contribui para o afastamento das clientes/pacientes do acompanhamento pré-natal, pois não ocorre estabelecimento de vínculos. Desta forma o distanciamento entre profissionais e mulheres fica evidente, uma vez que as necessidades destas são colocadas de lado, o que prejudica a relação de confiabilidade entre profissional e paciente (SILVA et al., 2016). 
O atendimento deve ser centrado no acolhimento, na comunicação (escuta), na interação, no comprometimento do enfermeiro e no estabelecimento de vínculos, a gestante deve tornar-se um "ser ativo" no processo de ser mãe, durante todo o atendimento deve respeitar-se a privacidade delas. A adequação as consultas se dá através dos recursos humanos e materiais disponíveis, assim como o espaço disposto para 0 atendimento e para a realização de atividades educativas, em relação ao espaço este deve proporcionar segurança a adolescente e ao prestador dos serviços, uma vez que neste local será exposto seus pensamentos, suas dúvidas seus medos; onde o profissional dará esclarecimentos em relação a educação em saúde variante em cada caso apresentado entende-se que está jovem é um ser integral com uma história particular (SILVA et al., 2016).

Segundo Silva et al. (2016), é durante a consulta de enfermagem que se colhe as informações pertinentes sobre o processo gestacional, é onde se dá o apoio e as orientações necessárias, busca-se a prevenção dos agravos, estabelece-se desenvolvimento de atividades em grupo para estimulação e inserção das adolescentes no pré-natal, favorecendo com isto um período gestacional tranquilo e com segurança fornecendo um ambiente seguro e favorável as ações educativas voltadas para promoção da saúde.

De acordo com Bittencourt (2010, p. 40) compete ao enfermeiro na Assistência ao Pré-Natal:

Captação precoce, Diagnóstico de gravidez- BHCG (Hormônio Beta Gonadotrofina Coriônica), Informação / orientação em saúde, Consulta de pré-natal de baixo-risco, Classificação de risco gestacional, Solicitação e avaliação de exames laboratoriais de rotina e USG obstétrica, Solicitação de exames complementares, Prescrição de Ácido Fólico e Sulfato Ferroso (segundo as normas e rotinas da instituição), Prescrição de vacinação antitetânica (dupla adulto), Visita domiciliar, Registro no cartão e ficha perinatal, Encaminhamentos para visita à maternidade, Registro no SISPRENATAL, Encaminhamento a odontologia e a nutrição.

Segundo o Ministério da saúde (2012) o atendimento durante o pré-natal poderá ser realizado nas unidades de saúde ou durante as visitas em domicílio, sendo o 
calendário de atendimento programado em função dos períodos gestacionais que determinam maior risco materno e perinatal, no entanto o calendário deve ser iniciado o mais precoce possível preferencialmente no primeiro trimestre devendo este está regular, pois as avaliações então propostas devem ser realizadas e anotadas corretamente tanto no Cartão da Gestante quanto na Ficha de Pré-Natal.

Fica ainda preconizado pelo Ministério da Saúde o mínimo de 6 (seis) consultas; devendo sempre que possível ser realizadas segundo o cronograma pré-estabelecido: Até $28^{\underline{a}}$ semana - mensalmente; Da $28^{\underline{a}}$ até a 36aㅗ semana quinzenalmente; Da $36^{\underline{a}}$ até a $41^{\text {a }}$ semana - semanalmente. $O$ aumento das visitas ao final da gravidez é determinado a avaliação dos riscos que antecedem o nascimento do bebê e das intercorrências clínico-obstétricas, sendo as mais comuns no trimestre, o trabalho de parto prematuro, pré-eclâmpsia e eclampsia, amniorrexe prematura e óbito fetal. Quando o parto não se iniciar até a $41^{\text {a }}$ semana, é necessário a avaliação do feto, incluindo a avaliação do índice do líquido amniótico e monitoramento cardíaco fetal desta forma é necessário que se faça o encaminhamento da gestante unidade de atendimento.

Dentre as atribuições do enfermeiro compete ainda a atuação como educador pois "a educação para a saúde é importante para o cuidado de enfermagem, uma vez que ela pode determinar como os indivíduos e as famílias são capazes de ter comportamentos que conduzam a um ótimo autocuidado" (ROCHA, 2013, p.16).

A educação em saúde não deve ser dada de forma exclusiva, sendo necessária a participação multiprofissional, ou seja, de todos as categorias que trabalham na saúde e que prestam assistência no período gestacional como psicólogo, assistente social, obstetra, dentista, enfermeiro, técnico de enfermagem dentre outros.

"O enfermeiro, como educador para a saúde, atua no intuito de preparar o indivíduo para o autocuidado e não para a dependência, sendo, portanto, um facilitador nas tomadas de decisões" (ROCHA,2013, p. 17).

De acordo com Andrade (2015, p. 22): 
O enfermeiro como profissional capacitado para assistir ao indivíduo em todas as etapas de vida, necessita estar inserida no Programa de Educação sexual das escolas. Provendo ações e programas voltados para a saúde do adolescente e sua família os quais devem atender as reais necessidades de ambos. É fundamental que todos, governo, profissionais de saúde e de educação, família, escola e sociedade não economizem, não só para exercer sua sexualidade, mas, principalmente para exercer seus direitos com responsabilidade, sendo respeitados e respeitando os outros.

As medidas para prevenção e/ou minimização do número de adolescentes grávidas está na implantação da educação sobre a sexualidade, o conhecimento do corpo e a reprodução humana. Esta educação deveria ser inserida nas escolas, assim como outras questões de cunho social como drogas e gravidez na adolescência, uma vez que é nas escolas que se concentram o maior número de jovens, no entanto é fundamental que haja a inserção e dos pais neste processo. Dentre as propostas de intervir na gravidez precoce pode-se tentar retardar o início das atividades sexuais, mas para aqueles que já estão sexualmente ativos espera-se adoção de medidas de cunho individual, que seria a educação sexual e o uso de contraceptivos. Os grupos de apoio poderiam ser então desenvolvidos e indicados para adolescentes que já confirmaram sua gravidez (ANDRADE, 2015).

\section{CONSIDERAÇÕES FINAIS}

Após a exposição da temática conclui-se que a gravidez na adolescência está diretamente relacionada a diversos fatores sociais, emocionais, econômicos e culturais. Sendo assim a assistência de Enfermagem deverá torna-se um vínculo entre os jovens e o mundo exterior a fim de minimizar do número de gestações na adolescência, uma vez que o ESF local passa a ser uma referência, buscando sempre compreender e responder qual o papel da equipe de enfermagem nesta assistência, visando sempre a promoção da qualidade de vida.

É função do enfermeiro vir a apresentar a essas adolescentes quais são os métodos contraceptivos e como devem ser manuseados, vindo então a tornar-se o instrumento primordial na prevenção da saúde de todos os jovens, mesmo que no momento a 
adesão encontra-se baixa a situação pode ser convertida deste que sejam implementadas novas propostas de intervenção e promoção da saúde.

A identificação por meio da literatura do número de adolescentes grávidas no Brasil nos permite fazer o levantamento de dados, possibilitando conhecermos, quais são as regiões que mais necessitam de atenção e quais os fatores que agravam este quadro, embora o ministério registre e informe a diminuição dos casos, não há garantias que este valor se torne nulo um dia.

O desenvolvimento das atividades direcionadas as adolescentes no período gravídico é de suma importância para melhor captação destas, o cuidado direto, o estabelecimento de vínculos e de metas, permitem conhecer o histórico de vida e fazer um acampamento de acordo com suas necessidades. As orientações devem ser sempre claras para melhor atendimento, jamais deverão ser realizados procedimentos que não estejam amparados pela lei do exercício profissional (Lei $n^{\circ}$ 7.498/86) e quando caracterizado como de alto risco necessitarão ser encaminhados ao serviço especializado.

\section{REFERÊNCIAS}

ALVES, Aline Salheb; LOPES, Maria Helena Baena de Moraes. Uso de métodos anticoncepcionais entre adolescentes universitários. Revista Brasileira de Enfermagem, Brasília, v. 61, n. 2, p. 170-177, mar/abr 2008. Disponível em: http://www.scielo.br/pdf/reben/v61n2/a05v61n2.pdf. Acesso em: 18 mai. 2018.

ANDRADE, Gabriela Chaves de. Atuação do enfermeiro do programa saúde da família na prevenção e controle da gravidez precoce. 2015. p. 33. Artigo (Pósgraduação em Saúde da Família) - Universidade Cândido Mendes, Rio de Janeiro, 2015.

ARAÚJO, R. L. D. et al. Gravidez na adolescência: consequências voltadas para a mulher. INTESA, Pombal-PB, v. 9, n. 1, p. 15-22, jan. 2015. Disponível em: 
http://www.gvaa.com.br/revista/index.php/INTESA/article/view/3189/2727.

Acesso em: 18 mai. 2018.

BITTENCOURT, Sibele Meneghel. Protocolo de atenção integral à saúde da mulher. 21. ed. Florianópolis, 2010. p. 127.

BRASIL. Governo do Brasil. Número de adolescentes grávidas cai $17 \%$ no Brasil, mai. 2017. Disponível em: http://www.brasil.gov.br/saude/2017/05/numero-deadolescentes-gravidas-cai-17-no-brasil. Acesso em: 13 abr. 2018.

BRASIL. Lei 8.069, de 13 de julho de 1990. Dispõe sobre o Estatuto da Criança e do Adolescente e dá outras providências. Presidência da República Casa Civil, Brasília, D.F., 13 jun. 1990. p. 1.

BRASIL. Lei n. 9.263, de 12 de janeiro de 1996. Regula o $\S 7^{\circ}$ de art. 226 da Constituição Federal, que trata do planejamento familiar, estabelece penalidades e dá outras providências.

Presidência da República Casa Civil, Brasília, D.F., 12 jan. 1996. p. 1.

BRASIL. Ministério da Saúde. Secretaria de Atenção à Saúde. Departamento de Ações Programáticas Estratégicas. Direitos sexuais, direitos reprodutivos e métodos anticoncepcionais. Ministério da Saúde, Brasília, caderno n. 2, 2009.

BRASIL. Ministério da Saúde. Saúde sexual e saúde reprodutiva. Ministério da saúde, Brasília, D.F., 2013, p. 300.

CARVALHO, A.Y.C. et al. Perfil sóciodemográfico e reprodutivo de adolescentes grávidas acompanhadas na Unidade Básica de Saúde do município de Canindé. Revista Reme. Fortaleza, v.10, n. 1, p. 53-61, jan/mar 2009. Disponível em: http://www.periodicos.ufc.br/rene/article/view/4729/3511. Acesso em: 18 mai. 2018.

DIAS, Mauro Henrique Tavares. Fatores que influenciam na não adesão de métodos contraceptivos durante a adolescência. Alagoas: Marechal Deodoro, 2015. Disponível em: 
https://www.nescon.medicina.ufmg.br/biblioteca/imagem/5012.pdf. Acesso em: 08 mar. 2018.

DINIZ, Eva; KOLLER, Silvia Helena. Fatores associados à gravidez em adolescentes brasileiros de baixa renda. Paidéia, Ribeirão Preto, v. 22, n. 53, p. 305-314, set/dez 2012. Disponível em: http://www.scielo.br/pdf/paideia/v22n53/02.pdf. Acesso em: 18 mai. 2018.

DOMINGOS, Andréia Couto. Gravidez na adolescência: Enfrentamento na Estratégia e Saúde da Família. Minas Gerais: Uberaba, 2010. Disponível em: https://www.nescon.medicina.ufmg.br/biblioteca/imagem/0299.pdf. Acesso em: 24 set. 2017.

DUARTE, Camila de Fátima; HOLANDA, Luana Brito; MEDEIROS, Michelle Loiola de. Avaliação de conhecimento contraceptivo entre adolescentes grávidas em uma unidade básica de saúde do distrito Federal. Curso de enfermagem da Universidade Paulista, Brasília-DF, v. 30, n. 2, abr/jun 2012. Disponível em: https://www.unip.br/comunicacao/publicacoes/ics/edicoes/2012/02_abrjun/V30_n2_2012_p140-143.pdf. Acesso em: 10 out. 2017.

FERREIRA, Cássia Regina de Arruda; RIBEIRO, Gracy Tadeu Ferreira. Aspectos socioeconômicos da gravidez na adolescência e as ações de saúde, o caso de Anápolis-GO. Vita et Sanitas, Trindade-GO, n. 4, p. 71-90, jan/dez 2010. Disponível em: http://www.fug.edu.br/2018/revista/index.php/VitaetSanitas/article/view/74/63. Acesso em: 18 mai. 2018.

HOGA, Luiza Akiko Komura. Maternidade na adolescência em uma comunidade de baixa renda: experiências reveladas pela história oral. Revista Latino Americana de Enfermagem. São Paulo, v.16, n.2, p.280-286, mar/abr 2008. Disponível em: http://www.scielo.br/pdf/rlae/v16n2/pt_17.pdf. Acesso em 18 mai. 2018.

JABOTÁ, Joana D’Arc Vila Nova; BASTOS, Othon. Depressão e ansiedade em adolescentes de escolas públicas e privadas. J. Bras. Psiquiatr., v. 56, n. 3, p. 171- 
179, 2007. Disponível em: http://www.scielo.br/pdf/jbpsiq/v56n3/a03v56n3.pdf. Acesso em: 18 mai. 2018.

LELIS, C.C.F et al. Aspectos Biopsicossociais de Puérperas Adolescentes no Município de João Pessoa. Revista Brasileira de Ciências da Saúde, Paraíba, Vol. 17, n. 4, p. 319-326, dez. 2013. Disponível em: http://www.periodicos.ufpb.br/index.php/rbcs/article/view/12254/11431. Acesso em: 18 mai. 2018.

LIMA, jade Silva e. Risco de trombose associado à terapia dos anticoncepcionais hormonais: uma revisão de literatura. 2017. p. 76. Monografia (Graduação em Farmácia) - Universidade Federal da Paraíba, João Pessoa, 2017.

MENEZES, Jaileila Araujo et al. Gravidez e maternidade na adolescência e suas repercussões no processo de escolarização. Revista Percursos, Florianópolis, v. 13, n. $2, \quad$ p. 134- 154, jul/dez. 2012. Disponível em: http://www.periodicos.udesc.br/index.php/percursos/article/viewFile/2497/2201. Acesso em: 18 mai. 2018.

MOREIRA, L.M.A. Métodos contraceptivos e suas características. 3. ed. Salvador: EDUFBA, 2011, p. 125-137.

MOREIRA, T. M. M. et al. Conflitos vivenciados pelas adolescentes com a descoberta da gravidez. Rev. esc. enferm. USP, São Paulo, v. 42, n. 2, p. 312-320, jun. 2008. Disponível em: http://www.scielo.br/pdf/reeusp/v42n2/a14.pdf. Acesso em: 18 mai. 2018.

NASCIMENTO, Mirlene Garcia; XAVIER, Patrícia Ferreira; SÁ, Rafaella Domingos Passos de. Adolescentes grávidas: a vivência no âmbito familiar e social. Revista Oficial do Núcleo de Estudos da Saúde do Adolescente, v. 8, n. 4, p. 41- 47, out/dez 2011.

Disponível: http://adolescenciaesaude.com/detalhe_artigo.asp?id=294\#. Acesso em: 17 mai. 2018. 
NÓBREGA, Líbne Lidianne da Rocha e; BEZERRA, Fernanda Patrícia Fernandes. Percepções de puérperas adolescentes frente à assistência de enfermagem no alojamento conjunto. Rev. Rene, v. 11, número especial, p. 42-52, 2010. Disponível em: www.periodicos.ufc.br/rene/article/download/4657/3475. Acesso em: 18 mai. 2018.

OLIVEIRA, E.M.A. et al. Histórico contraceptivo de adolescentes grávidas e seus sentimentos quanto a gravidez e ao futuro profissional. Revista Eletrônica de Enfermagem, [S. I.], v.10, n.2, p. 484-490, jun. 2008. Disponível em: https://www.fen.ufg.br/revista/v10/n2/pdf/v10n2a19.pdf. Acesso em: 18 mai. 2018.

PRIETSCH, Silvio Omar Macedo et al. Gravidez não planejada no extremo Sul do Brasil: prevalência e fatores associados. Cadernos de Saúde Pública, Rio de Janeiro, v. 27, n. 10, p. 1906-1976, out. 2011. Disponível em: http://www.scielo.br/pdf/csp/v27n10/04.pdf. Acesso em: 18 mai. 2018.

RANGEL, D.L.O. et al. A representação social as adolescentes sobre a gravidez nesta etapa da vida. Esc. Anna Nery Rev. Enferm, Rio de Janeiro, vol.12, n. 4, p. 780-788, dez. 2008. Disponível em: http://www.scielo.br/pdf/ean/v12n4/v12n4a24.pdf. Acesso em: 18 mai. 2018.

ROCHA, Monique Carolina de Jesus. Gravidez na Adolescência: a importância do enfermeiro como educador. 2013. p. 24 . TCC (Pós-graduação em Atenção básica EM Saúde da Família) - Universidade Federal de Minas Gerais, Belo Horizonte, 2013.

SANTOS, Carolina Carbonell dos. A vivência da gravidez na adolescência no âmbito familiar e social. Rev. Enferm UFSM, v. 4, n. 1, p. 105- 112, jan/mar 2014. Disponível em: https://periodicos.ufsm.br/reufsm/article/view/9860/pdf. Acesso em: 18 mai. 2018.

SILVA, C.S. et al. Atuação do enfermeiro na consulta pré natal: limites e potencialidades. Revista de Pesquisa Cuidado é Fundamental Online, Rio de Janeiro, v. 8 , n. 2, p. 4087-4098, abr/jun 2016. Disponível em: http://www.seer.unirio.br/index.php/cuidadofundamental/article/view/2009/pdf_1840. Acesso em: 18 mai. 2018. 
SILVA, Jaqueline Miranda Barros et al. Percepção de adolescentes grávidas acerca de sua gravidez. Revista Bahiana de Enfermagem, Salvador, v. 25, n. 1, p. 23-32, jan/abr. 2011. Disponível em: https://portalseer.ufba.br/index.php/enfermagem/article/view/5234/4324. Acesso em: 18 mai. 2018.

UNFPA (2017). Mundos Distantes: saúde e direitos reprodutivos em uma era de desigualdade. Situação da População Mundial 2017. Disponível em: https://popdesenvolvimento.org/noticias/saude-sexual-e-reprodutiva/564-relatoriounfpa-mundos-distantes-saude-e-direitos-reprodutivos-numa-era-de-desigualdade. Acesso em: 19 mai. 2018

Enviado: Julho, 2019.

Aprovado: Setembro, 2019. 